\title{
Nasal decolonization of Staphylococcus aureus and the risk of surgical site infection after surgery: a meta-analysis
}

Jia Tang ${ }^{1+}$, Jiangjin $\mathrm{Hui}^{2+}$, Jing $\mathrm{Ma}^{3+}$ and Chen Mingquan ${ }^{1,4^{*}}$

\begin{abstract}
Aim: To assess the effects of nasal decontamination on preventing surgical site infections (SSIs) in people who are Staphylococcus aureus carriers undergoing different types of surgeries and diverse measures of decolonization.

Methods: Relevant randomized controlled trials (RCTs) were identified through systematic searches of the PubMed, Embase, Web of science, and the Cochrane Library databases. The risk ratios (RRs) and 95\% confidence intervals (Cls) were calculated and the effects model was chosen according to the heterogeneity. Subgroup analyses were performed according to different types of surgeries and measures of decolonization that Staphylococcus aureus carriers were applied.

Results: Twenty RCTs published between 1996 and 2019 involving 10,526 patients were included. Pooled results showed that the overall SSIs and pulmonary surgery SSIs presented with a statistical difference in measures of nasal decontamination ( $R R=0.59$ and 0.47 , respectively, both $p<0.01$ ). However, the associations between nasal decolonization and increased risks of SSIs in orthopedics surgery or cardiovascular surgery remained insignificant in studies. As for the diverse measures of nasal decontamination, 50\% used mupirocin, 15\% used chlorhexidine, 30\% used different types of antimicrobial drugs, and $5 \%$ use others. The SSIs rate were decreased after chlorhexidine $(\mathrm{RR}=0.474,95 \% \mathrm{Cl}$ 0.259-0.864), while no significant difference was shown in the use of mupirocin ( $R R=0.871,95 \% \mathrm{Cl} 0.544-1.394)$.
\end{abstract}

Conclusion: It seems that nasal decolonization of Staphylococcus aureus may be associated with a reduction of SSIs in these patients, especially in patients who have been administered by pulmonary surgeries or treated with chlorhexidine.

Keywords: Nasal decolonization, Staphylococcus aureus, Surgical site infections, Meta-analysis

\section{Introduction}

Staphylococcus aureus (S. aureus), which is normally presented in the microbiota of the human skin and is generally asymptomatic. It remains one of the most common drug-resistant pathogens that causes infection in hospitalized patients $[1,2]$. Investments in infection reduction

\footnotetext{
*Correspondence: tangsweetness@163.com

†Jia Tang, Jiangjin Hui and Jing Ma contributed equally to this work

${ }^{4}$ Department of Emergency, Huashan Hospital, Fudan University, Shanghai 200040, China

Full list of author information is available at the end of the article
}

have been posed in intensive care units, which has been defined as an "epicenter" of nosocomial infections, by measurements of skin decolonization involving daily chlorhexidine bathing [3]. The practice was adopted because of evidence that universal decolonization reduces device-associated bacteremia, all-cause bacteremia, and multidrug-resistant organisms [3, 4]. However, the nasal carriage is also unavoidable for endogenous infections and for transmission to other individuals, as the colonization of extra nasal sites often originates from the nasal reservoir [5]. S. aureus nasal carriage has been extensively studied by numerous studies, as it was the

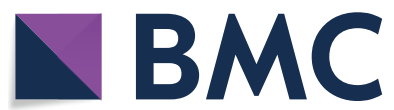

(c) The Author(s) 2020. This article is licensed under a Creative Commons Attribution 4.0 International License, which permits use, sharing, adaptation, distribution and reproduction in any medium or format, as long as you give appropriate credit to the original author(s) and the source, provide a link to the Creative Commons licence, and indicate if changes were made. The images or other third party material in this article are included in the article's Creative Commons licence, unless indicated otherwise in a credit line to the material. If material is not included in the article's Creative Commons licence and your intended use is not permitted by statutory regulation or exceeds the permitted use, you will need to obtain permission directly from the copyright holder. To view a copy of this licence, visit http://creativecommons.org/licenses/by/4.0/. The Creative Commons Public Domain Dedication waiver (http://creativecommons.org/publicdomain/zero/1.0/) applies to the data made available in this article, unless otherwise stated in a credit line to the data. 
most common pathogen associated with a postoperative surgical site infections (SSIs), what remains unclear is the exact source of the pathogen [6].

It has been shown that being a nasal carrier of S. aureus is a significant risk factor for developing a SSI [7]. In this regard, it seems that the number of SSIs acquired in hospitals may be reduced by decolonization of nasal $S$. aureus carriage on admission [8]. Special attention was paid to nasal decontamination for prevention of SSIs in $S$. aureus carriers. The results of several RCTs in different hospitals and institutions are still mixed and inconclusive, limited by the population and surgery form $[6,9]$. The aim of the study is to evaluate the use of nasal decontamination in different types of surgery and provide some evidence that makes efforts to measure of infection control and prevention.

\section{Methods}

This study was performed in accordance with the guideline of Preferred Reporting Items for Systematic Reviews and Meta Analyses [10] and Cochrane's Handbook [11] guidelines. A prospective protocol was registered in advance and uploaded to the PROSPERO online platform. The registration number is CRD42020170139.

\section{Literature search}

We searched English literature in PubMed, Embase, Web of science, and the Cochrane Library using combinations of the following terms: (1)Nasal or Nose; (2) Staphylococcus aureus; (3) Mupirocin or Chlorhexidine or Decontamination. We limited the search to human studies published in randomized trials. All databases were searched from the date of inception up to 20 December 2019. The search strategy used in PubMed is shown in Additional file 1: Appendix S1.

\section{Eligibility criteria}

Studies were eligible for this review if they met the following criteria: (1) a randomized controlled trial of human; (2) had to describe the standard microbial isolation and identification, like $S$. aureus, MRSA or MSSA; (3) included patients scheduled for surgery without infectious diseases. Reviews, case reports, conference abstracts, animal experiments, letters, editorials and studies without randomization were excluded.

\section{Data extraction and quality evaluation}

Data from appropriate studies were pulled out independently by authors and potted into a spreadsheet. Inconsistencies were resolved by unanimity. The data extracted included (1) first author, location, and study design characteristics; (2) procedure characteristics and number, mean age, and gender of patients; (3) methods for screening of nasal S. aureus colonization, and strategies for decolonization for nasal MRSA carriers; (4) types of surgery and SSIs; (5) total numbers of $S$. aureus patients and non-colonized patients according to the results of nasal swab examination and the number of patients with SSIs in each group after surgeries. Study quality evaluation was performed with the Cochrane risk of bias tool [11] which includes allocation concealment, blinding, outcome assessment, loss to follow-up (attrition), and the extent of imbalance of the study arms at the beginning of the trial.

\section{Statistical analyses}

We performed a meta-analysis to estimate pooled relative risks (RRs) and 95\% confidence intervals (CIs) in STATA version 13.0 (StataCorp, College Station, TX, USA). Heterogeneity was assessed by the $\mathrm{I}^{2}$ statistic, for which an $\mathrm{I}^{2}>50 \%$ suggested substantial heterogeneity and vice versa. In this, $\mathrm{I}^{2}$ values of $<25 \%, 25-50 \%, 50-75 \%$, and $>75 \%$, were suggestive of low, moderate, substantial, and considerable heterogeneity, respectively. The effects model was chosen according to the heterogeneity. If the $\mathrm{I}^{2}$ was $\leq 50 \%$, fixed effect model should be applied while $\mathrm{I}^{2}>50 \%$ random effect model should be applied. Furthermore, visual assessment of publication bias was shown using the funnel plot. In our study, $\mathrm{p}<0.05$ was considered a significant difference.

\section{Results \\ Study selection}

The study selection process is presented in Fig. 1. A total of 1271 relavent studies were searched. 681 studies were subjected to abstract review, excluding many reviews, letters, conference abstracts, editorials and laboratory studies. The remaining 30 studies were subjected to full-text review to exclude those with irrelevant subjects or those that did not fully meet the inclusion criteria. Ultimately, 20 studies were included in the meta-analyses [12-31].

\section{Study characteristics and quality assessment}

The characteristics of the included studies are presented in Table 1. The studies were published between 1996 and 2019 and performed in the United States [14, 17, 18, 21, 24, 26], Netherlands [16, 28-30], and Australia [19, 23, 31 . Besides, the quality of included articles according to Cochrane's Book was shown in Fig. 2.

\section{Nasal decolonization and the risk of overall SSIs after surgery}

The pooled results from 20 studies [12-31] accounting of 10,526 patients showed that nasal decolonization may be associated with a significantly decreased risk of overall SSI in patients after surgery $(R R=0.59,95 \% \mathrm{CI}$ 
Articles identified through databases searching ( $n=1271)$ : Pubmed ( $n=261)$; Embase $(n=323)$; Cochrance library $(n=347)$; Web $(n=340)$;

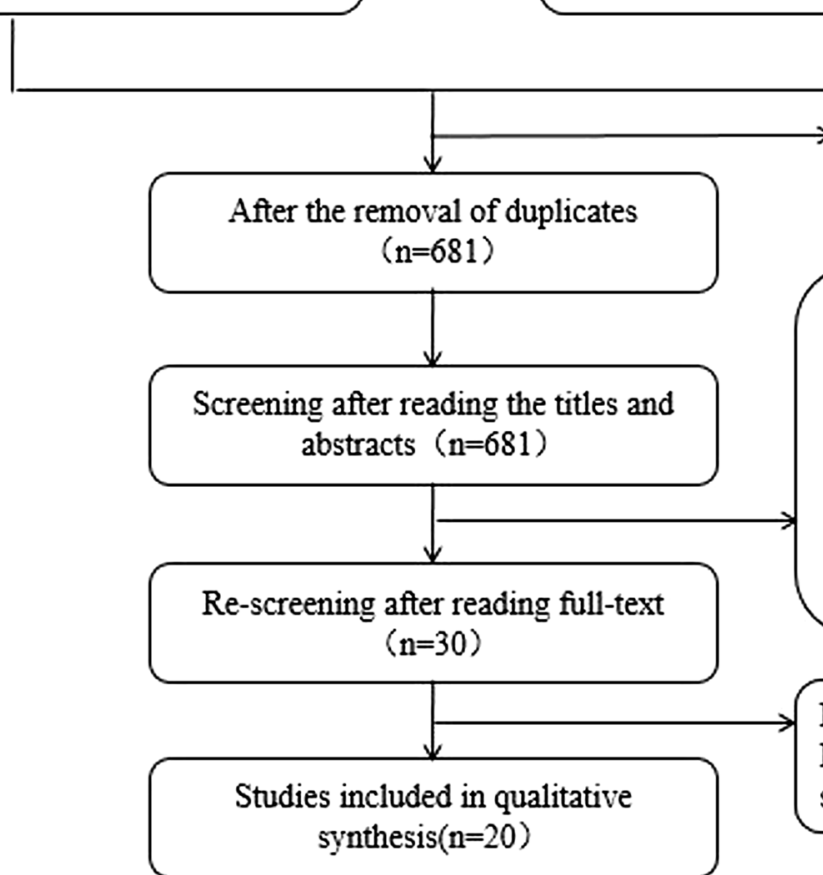

Additional articles identified through other sources $(n=0)$

duplicates $(n=590)$

Records excluded ( $\mathrm{n}=629)$ :

Reviews(n=129);

irrelevant studies ( $\mathrm{n}=141)$;

irrelevant RCT ( $n=70)$;

system evaluation ( $\mathrm{n}=25)$;

case report or conference $(n=27)$

irrelevant research content $(n=238)$

RCT without full-text $(n=22)$

Records excluded ( $n=5)$ :

RCT with irrelevant content $(n=3)$; studies with inadequate data $(n=7)$

Fig. 1 Flow chart

Table 1 Characteristics of the included studies

\begin{tabular}{|c|c|c|c|c|c|c|c|c|}
\hline & First author & Year & Country & Design & Types of surgery & Number & Age & Intervention \\
\hline 1 & Akira & 2006 & Japan & RCT & Endoscopic gastrostomy & 48 & $73-74$ & $\begin{array}{l}\text { Mupirocin, arbekacin, and sulfameth- } \\
\text { oxazole/trimethoprim vs untreated }\end{array}$ \\
\hline 2 & Xavier & 2018 & Germany & RCT & Lung cancer surgery & 450 & $49-9$ & $\begin{array}{l}\text { Chlorhexidine gluconate (CHG) vs } \\
\text { placebo }\end{array}$ \\
\hline 3 & Laura & 2014 & American & RCT & Lung cancer surgery & 365 & $55.5-77.9$ & Chlorhexidine vs untreated \\
\hline 4 & Guy & 2016 & Israel & $\mathrm{RCT}$ & Cesarean section & 568 & $26.8-37.4$ & Mupirocin vs control \\
\hline 5 & Albertine & 1998 & Netherlands & $\mathrm{RCT}$ & Orthopedics & 100 & 18 vs 10 & Mupirocin vs control \\
\hline 6 & Michael & 2014 & American & $\mathrm{RCT}$ & Arthroplasty or spine fusion & 1697 & $19.1-93.2$ & Mupirocin vs iodine \\
\hline 7 & Nalini & 2008 & American & RCT & Joint arthroplasty & 1377 & NA & Mupirocin vs TJA \\
\hline 8 & Helena & 2018 & Australia & RCT & Dermatological closures & 142 & $55.2-77.4$ & Cephalexin vs placebo \\
\hline 9 & Saleh & 2016 & Sweden & RCT & Dermatological closures & 40 & 45-92 & PHMB-based solution vs sterile water \\
\hline 10 & Shuman & 2012 & American & $\mathrm{RCT}$ & Head and neck surgery & 84 & $57.5-58.14$ & $\begin{array}{l}\text { Topical antimicrobial decolonization vs } \\
\text { standard prophylaxis alone }\end{array}$ \\
\hline 11 & Talesh & 2017 & Iran & $\mathrm{RCT}$ & Head and neck surgery & 44 & $19.7-45.3$ & Mupirocin vs untreated \\
\hline 12 & Yee & 2013 & Australia. & RCT & Mohs micrographic surgery & 738 & $64-67$ & Mupirocin vs untreated \\
\hline 13 & Berg & 2004 & American & RCT & Cardiac surgery & 296 & $54.4-72.2$ & Clarithromycin vs placebo \\
\hline 14 & Konvalinka & 2006 & Canada & RCT & Cardiac surgery & 257 & $51.7-73.3$ & Mupirocin vs placebo \\
\hline 15 & Zibari & 1997 & American & RCT & Thrombectomized grafts surgery & 408 & $17-81$ & Vancomycin vs not vancomycin \\
\hline 16 & Andenaes & 1996 & Norway & $\mathrm{RCT}$ & Orthopedics & 339 & 24 & Azithromycin vs placebo \\
\hline 17 & Bode & 2016 & Netherlands & $\mathrm{RCT}$ & Cardiac surgery & 793 & NA & Mupirocin vs placebo \\
\hline 18 & Kalmeijer & 2002 & Netherlands & $\mathrm{RCT}$ & Orthopedics & 614 & $48.1-77.3$ & Mupirocin vs placebo \\
\hline 19 & Kluytmans & 1998 & Netherlands & $\mathrm{RCT}$ & Lung cancer surgery & 816 & NA & Chlorhexidine vs placebo \\
\hline 20 & Smith & 2019 & Australia & $\mathrm{RCT}$ & Mohs micrographic surgery & 1350 & $51-81$ & Mupirocin vs untreated \\
\hline
\end{tabular}




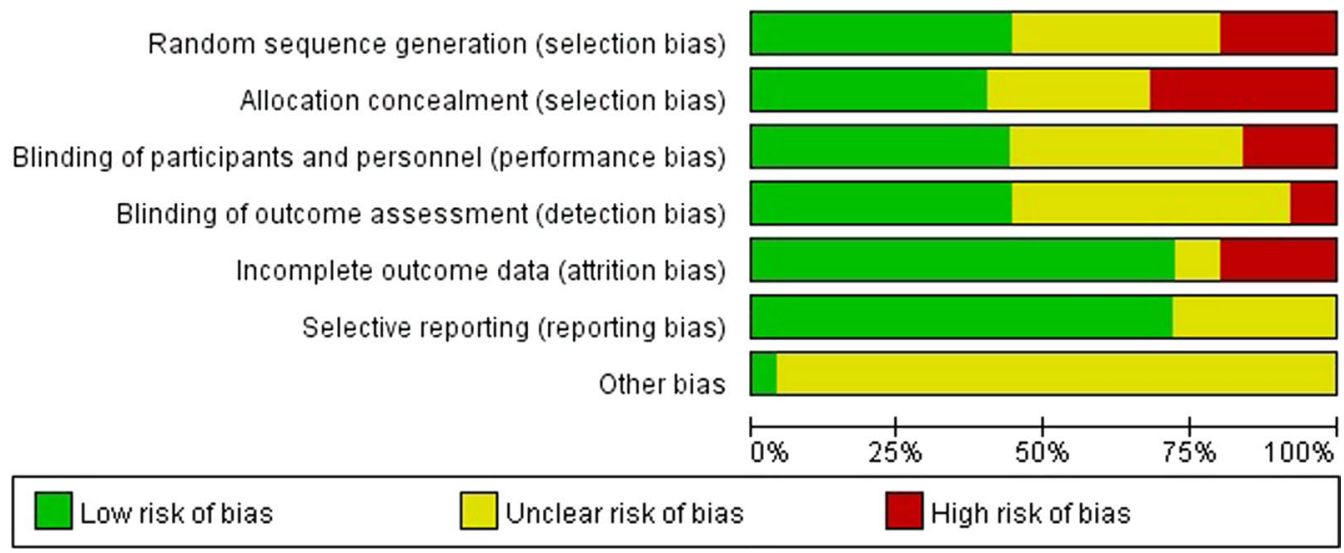

Fig. 2 The quality assessment of included articles

0.38-0.90; Fig. 3). Random effects model was chosen to balance the statistical heterogeneity ( $\mathrm{p}$ for Cochrane's $\mathrm{Q}$ test $=0.000, \mathrm{I}^{2}=75.8 \%$ ). Thus, further subgroups analyses were posed to illustrate specific relationships.

\section{Nasal decolonization and the risk of SSIs after orthopedics surgery}

Three articles [16-18] with 3174 patients reported the SSIs and orthopedics surgery, showing that there was no statistical difference $(R R=0.68,95 \%$ CI $0.16-2.82$; Fig. 4). The substantial heterogeneity (p for Cochrane's $Q$ test $=0.009, \mathrm{I}^{2}=78.8 \%$ ) was demonstrated with analysis of random model.

\section{Nasal decolonization and the risk of SSIs after cardiovascular surgery}

Four studies [24-28] enrolled 1754 patients comparing the decolonization in cardiovascular surgeries. No statistical difference was detected in the meta-analysis $(\mathrm{RR}=0.33$, 95\% CI 0.08-1.35; Fig. 5). Statistical heterogeneity ( $\mathrm{p}$ for Cochrane's $\mathrm{Q}$ test $=0.000, \mathrm{I}^{2}=86.0 \%$ ) was handled in random model.

\section{Nasal decolonization and the risk of SSI after pulmonary surgery}

Pooled estimates from three studies [13, 14, 30] presented that nasal decolonization related to a significantly decreased risk of SSI in patients after pulmonary surgery $(\mathrm{RR}=0.47$, 95\% CI 0.30-0.73; Fig. 6). Moreover, no significant heterogeneity was detected ( $\mathrm{p}$ for Cochrane's $\mathrm{Q}$ test $\left.=0.20, \mathrm{I}^{2}=37.9 \%\right)$.

\section{Nasal decolonization and the risk of SSI with different interventions}

The interventions of decolonization were diverse, showing that 50\% used mupirocin, 15\% used chlorhexidine,
$30 \%$ used different types of antimicrobial drugs, and 5\% use others. As for that, ten articles comparing mupirocin with untreated administration, no significant difference was concluded ( $R R=0.87,95 \%$ CI 0.54-1.39; Fig. 7), while the heterogeneity was detected and balanced through random model ( $\mathrm{p}$ for Cochrane's $\mathrm{Q}$ test $=0.33$, $\left.\mathrm{I}^{2}=67.9 \%\right)$. However, there was a decreased risk of SSI in patients after chlorhexidine, with statistical difference $(R R=0.45,95 \%$ CI $0.28-0.72$; Fig. 8), and no significant heterogeneity was detected ( $\mathrm{p}$ for Cochrane's $\mathrm{Q}$ test $\left.=0.22, \mathrm{I}^{2}=33.8 \%\right)$.

\section{Publication bias}

Funnel plots for the associations between nasal S. aureus decolonization and overall SSI risks were shown in Additional file 2: Appendix S2. The funnel plots were symmetric on visual inspection.

\section{Discussion}

Our systematic review has identified important gaps in the literature on targeted decolonization strategies in Staphylococcus aureus carriers with different types of surgery. The overall SSIs and pulmonary surgery SSIs presented with a statistical difference in measures of nasal decontamination.

In an early meta-analysis of two randomized trials in cardiac surgery patients, limited by the number of studies, the results showed that no clear difference in SSI risk following the use of mupirocin compared with placebo (RR 1.60, 95\% CI 0.79 to 3.25) [9, 25]. Moreover, a recent meta-analysis [32] reported that nasal MRSA colonization may be associated with increased risks of overall SSI and MRSA-SSI after spine surgeries through seven studies $(R R=2.52$ and 6.21, respectively, both $p<0.001)$. Furthermore, a prospective, randomized, single-blinded trial, mentioned about SSIs after elective orthopedic surgery, 


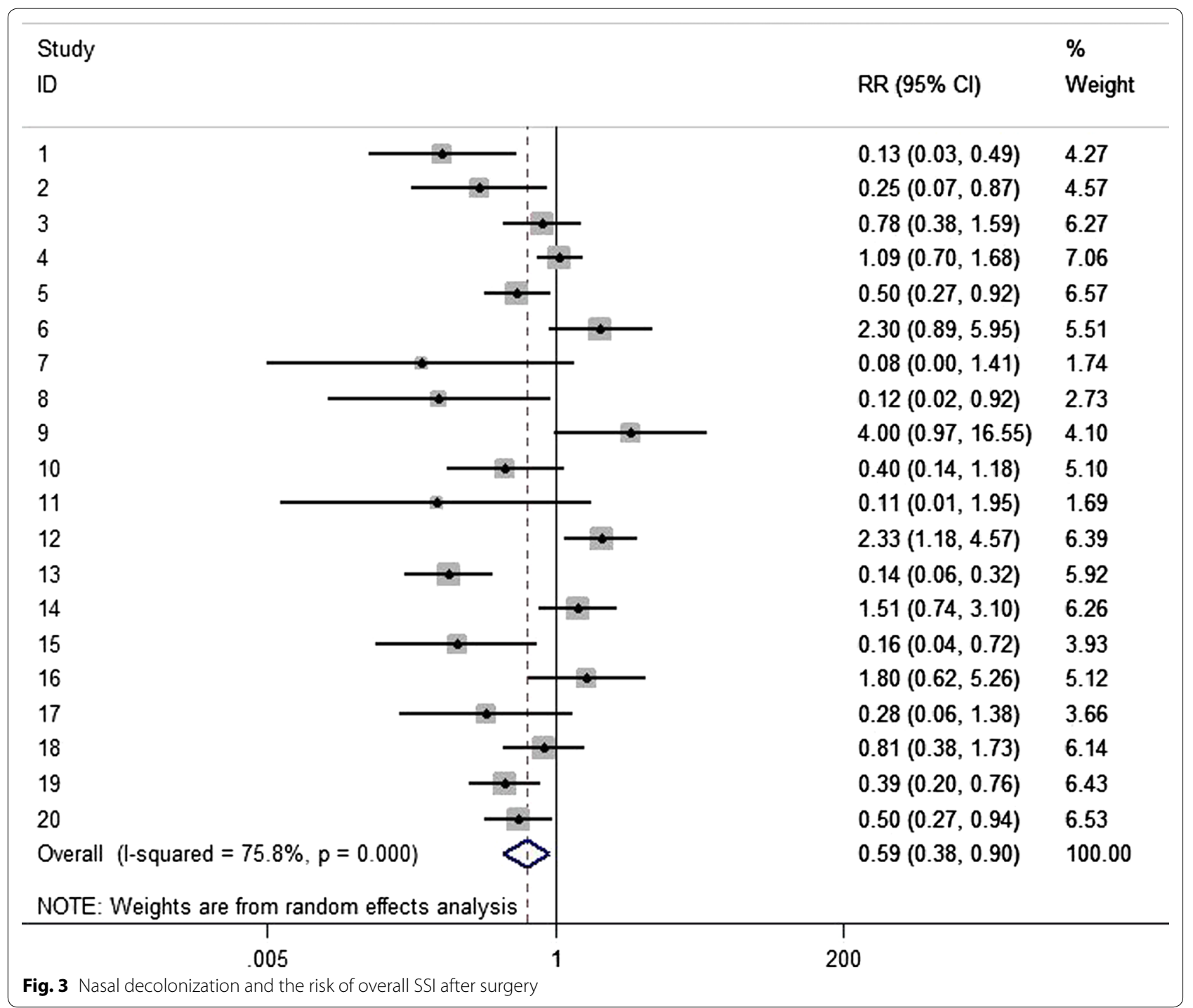

found that no difference in the risk of SSI between the decolonization and control groups in 1318 patients, both in S. aureus carriers and non-carriers [33]. Different results could also be found in another RCT [3], Huang et al. found decolonization with universal chlorhexidine bathing and targeted mupirocin for MRSA carriers did not significantly reduce multidrug-resistant organisms in non-critical-care patients. In light of this, more prospective, randomized-controlled, multi-center studies were needed to articulate the relationships among them.

Trojan Horse [34] claimed a hypothesis trying to explain SSI pathogenesis, showing that pathogens remote from the SSI area-such as within the teeth, noses, or gastrointestinal tract-can be taken up by immune cells (macrophages or neutrophils) and travel to the wound site where they cause wound infections. This mechanism could be verified in a mice model, which can also explain why some infections occur latently following surgery and are due to organisms not found in the wound at the end of the operation $[6,35]$.

Several limitations derived from this systematic review must be acknowledged. First, the number of included randomized studies was small, which prevented us from evaluating the potential influences of strains of $S$. aureus (e.g. hospital-associated MRSA/MSSA, community-associated MRSA/MSSA) on the association between nasal $S$. aureus colonization and SSIs events. In addition, some studies involved in this study are in high risk and high heterogeneity, which might result in inevitable bias. Last but not least, the adverse effects of decolonization (e.g. increased risk of drug resistance) had been merely mentioned, which is significant for an appliance. 
Study

ID

1

2

3

Overall $(\mathrm{I}-$ squared $=78.8 \%, p=0.009)$

NOTE: Weights are from random effects analysis

\section{.005}
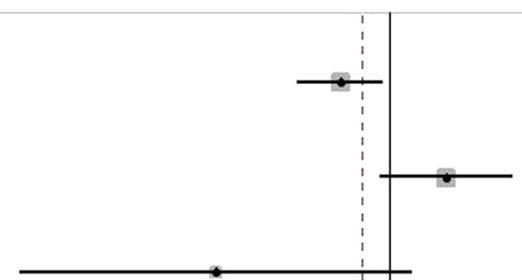

$\%$

$\operatorname{RR}(95 \% \mathrm{Cl}) \quad$ Weight

$0.50(0.27,0.92) 43.89$

$2.30(0.89,5.95) 39.43$

$0.08(0.00,1.41) 16.68$

$0.68(0.16,2.82) 100.00$

Fig. 4 Nasal decolonization and the risk of SSI after orthopedics surgery

\begin{tabular}{|c|c|c|}
\hline Study & & $\%$ \\
\hline ID & $\mathrm{RR}(95 \% \mathrm{Cl})$ & Weight \\
\hline 1 & $0.14(0.06,0.32)$ & 27.42 \\
\hline 2 & $1.51(0.74,3.10)$ & 28.04 \\
\hline 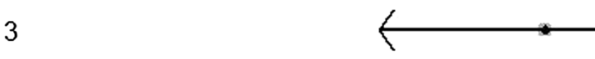 & $0.16(0.04,0.72)$ & 22.69 \\
\hline 4 & $0.28(0.06,1.38)$ & 21.85 \\
\hline Overall $(\mathrm{I}$-squared $=86.0 \%, p=0.000 \%$ & $0.33(0.08,1.35)$ & 100.00 \\
\hline NOTE: Weights are from random effects analysis & & \\
\hline
\end{tabular}

Fig. 5 Nasal decolonization and the risk of SSI after cardiovascular surgery

To conclude, the main pillars of from available evidence, it seems that nasal decontamination may be associated with a reduction of overall SSIs in patients with pulmonary surgery or treated with chlorhexidine. Further studies are needed to validate and propose the specific relationships between host and infection. 
Study

ID

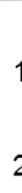

1

2

3

Overall (l-squared $=37.9 \%, p=0.200)$

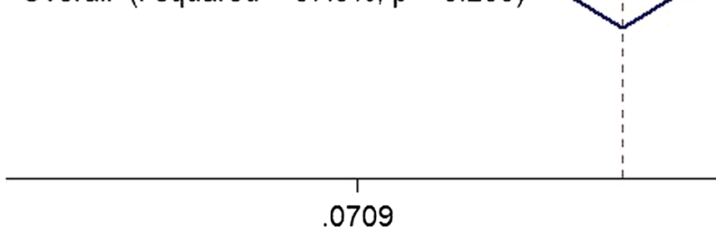

$\%$

$\mathrm{RR}(95 \% \mathrm{Cl}) \quad$ Weight

$0.39(0.20,0.76) \quad 51.17$

$0.25(0.07,0.87) 21.15$

$0.78(0.38,1.59) \quad 27.69$

$0.47(0.30,0.73) \quad 100.00$

Fig. 6 Nasal decolonization and the risk of SSI after pulmonary surgery

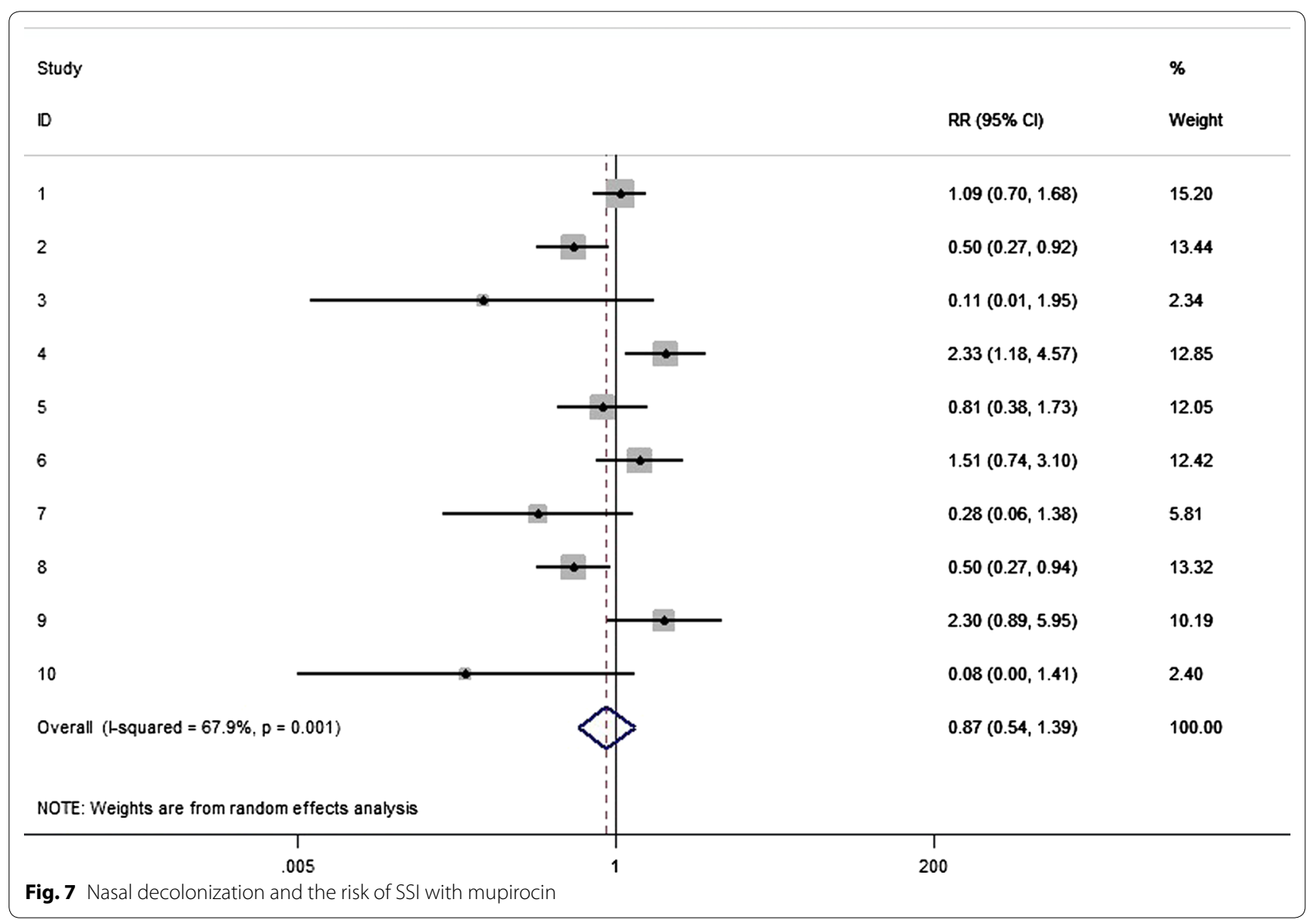


Study

ID

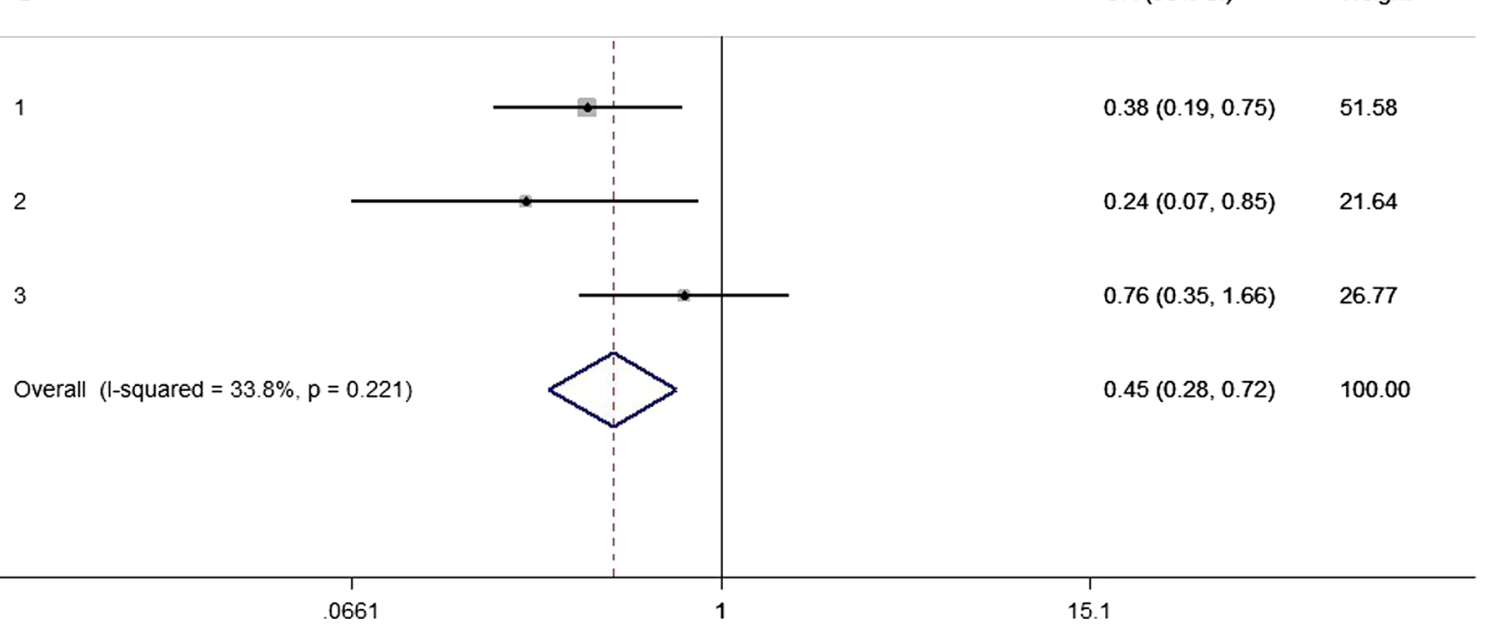

$\%$

Weight

Fig. 8 Nasal decolonization and the risk of SSI with chlorhexidine

\section{Supplementary information}

Supplementary information accompanies this paper at https://doi. org/10.1186/s12941-020-00376-w.

Additional file 1. Search strategy.

Additional file 2. Funnel plot.

\section{Abbreviations}

SSIs: Surgical site infections; RCTs: Randomized controlled trials; RRs: Risk ratios; Cls: Confidence intervals; S. aureus: Staphylococcus aureus; MRSA: Methicillinresistant Staphylococcus aureus; MSSA: Methicillin-sensitive Staphylococcus aureus.

\section{Acknowledgements}

Not applicable. This article has not been published elsewhere in whole or in part.

\section{Authors' contributions}

$\mathrm{JT}$ and $\mathrm{JH}$ : Design the research direction, acquisition and interpretation of data, technical procedures, analyzed and interpreted the patient data, drafted the initial manuscript, approved the final manuscript, supervised all phases of the study. JM: Acquisition and interpretation of data, technical procedures, drafted the initial manuscript, and approved the final manuscript. CM: Design the research direction, approved the final manuscript, supervised all phases of the study. All authors read and approved the final manuscript.

\section{Funding}

This study was supported by National Natural Science Foundation of China (81773088).

\section{Availability of data and materials}

All data generated or analysed during this study are included in this published article and its additional files.

Ethics approval and consent to participate Not applicable.

\section{Consent for publication}

Not applicable.

\section{Competing interests}

The authors declare that they have no competing interests.

\section{Author details}

${ }^{1}$ Department of Infectious Diseases and Hepatology, Huashan Hospital, Fudan University, Shanghai 200040, China. ${ }^{2}$ Department of Infectious Diseases, The First Affiliated Hospital of Zhejiang University, Hangzhou 310003, China.

${ }^{3}$ Department of Endocrinology and Metabolism, Gansu Provincial Hospital, Lanzhou 730000, China. ${ }^{4}$ Department of Emergency, Huashan Hospital, Fudan University, Shanghai 200040, China.

Received: 19 May 2020 Accepted: 24 July 2020

Published online: 30 July 2020

\section{References}

1. Sampedro GR, Bubeck Wardenburg J. Staphylococcus aureus in the intensive care unit: are these golden grapes ripe for a new approach? J Infect Dis. 2017;215(suppl_11):S64-70. https://doi.org/10.1093/infdis/jiw581.

2. Pacifico $C$, Hilbert $M$, Sofka D, et al. Characterization of bacteria and inducible phages in an intensive care unit. J Clin Med. 2019. https://doi. org/10.3390/jcm8091433.

3. Huang SS, Septimus E, Kleinman K, et al. Chlorhexidine versus routine bathing to prevent multidrug-resistant organisms and all-cause bloodstream infections in general medical and surgical units (ABATE Infection trial): a cluster-randomised trial. Lancet. 2019;393(10177):1205-15. https ://doi.org/10.1016/s0140-6736(18)32593-5.

4. Septimus E, Hickok J, Moody J, et al. Closing the translation gap: toolkitbased implementation of universal decolonization in adult intensive care units reduces central line-associated bloodstream infections in 95 community hospitals. Clin Infect Dis. 2016;63(2):172-7. https://doi. org/10.1093/cid/ciw282.

5. Wertheim HF, Vos MC, Ott A, et al. Risk and outcome of nosocomial Staphylococcus aureus bacteraemia in nasal carriers versus non-carriers. Lancet. 2004;364(9435):703-5. https://doi.org/10.1016/s0140-6736(04)16897-9. 
6. Alverdy JC, Hyman N, Gilbert J. Re-examining causes of surgical site infections following elective surgery in the era of asepsis. Lancet Infect Dis. 2020. https://doi.org/10.1016/s1473-3099(19)30756-X.

7. Pelfort X, Romero A, Brugues M, et al. Reduction of periprosthetic Staphylococcus aureus infection by preoperative screening and decolonization of nasal carriers undergoing total knee arthroplasty. Acta Orthop Traumatol Turc. 2019;53(6):426-31. https://doi.org/10.1016/j.aott.2019.08.014.

8. Mehraj J, Witte W, Akmatov MK, et al. Epidemiology of Staphylococcus aureus nasal carriage patterns in the community. Curr Top Microbiol Immunol. 2016;398:55-87. https://doi.org/10.1007/82_2016_497.

9. Liu Z, Norman G, Iheozor-Ejiofor Z, et al. Nasal decontamination for the prevention of surgical site infection in Staphylococcus aureus carriers. Cochrane Database System Rev. 2017;5:CD012462. https://doi. org/10.1002/14651858.cd012462.pub2.

10. Moher D, Liberati A, Tetzlaff J, et al. Preferred reporting items for systematic reviews and meta-analyses: the PRISMA Statement. Open Med. 2009;3(3):e123-30.

11. Cumpston M, LiT, Page MJ, et al. Updated guidance for trusted systematic reviews: a new edition of the Cochrane handbook for systematic reviews of interventions. Cochrane Database Syst Rev. 2019;10:ED000142. https://doi.org/10.1002/14651858.ed000142.

12. Horiuchi A, Nakayama Y, Kajiyama M, et al. Nasopharyngeal decolonization of methicillin-resistant Staphylococcus aureus can reduce PEG peristomal wound infection. Am J Gastroenterol. 2006;101 (2):274-7. https ://doi.org/10.1111/j.1572-0241.2006.00366.x.

13. D'Journo XB, Falcoz PE, Alifano M, et al. Oropharyngeal and nasopharyngeal decontamination with chlorhexidine gluconate in lung cancer surgery: a randomized clinical trial. Intensive Care Med. 2018;44(5):578-87. https://doi.org/10.1007/s00134-018-5156-2.

14. Grimmer LE, Stafford TS, Milman S, et al. Efficacy of pre-operative nasal Staphylococcus aureus screening and chlorhexidine chest scrub in decreasing the incidence of post-resection empyema. Surg infect. 2014;15(2):118-22.

15. Shrem G, Egozi T, Naeh A, et al. Pre-cesarean Staphylococcus aureus nasal screening and decolonization: a prospective randomized controlled trial. J Mater-Fetal Neonatal Med. 2016;29(23):3906-11. https://doi. org/10.3109/14767058.2016.1152243.

16. van der Gernaat Sluis AJ, Hoogenboom-Verdegaal AM, Edixhoven PJ, et al. Prophylactic mupirocin could reduce orthopedic wound infections. 1044 patients treated with mupirocin compared with 1260 historical controls. Acta Orthop Scand. 1998;69(4):412-4. https://doi.org/10.3109/17453 679808999058

17. Phillips M, Rosenberg A, Shopsin B, et al. Preventing surgical site infections: a randomized, open-label trial of nasal mupirocin ointment and nasal povidone-iodine solution. Infect Control Hosp Epidemiol. 2014;35(7):826-32. https://doi.org/10.1086/676872.

18. Rao N, Cannella B, Crossett LS, et al. A preoperative decolonization protocol for staphylococcus aureus prevents orthopaedic infections. Clin Orthop Relat Res. 2008;466(6):1343-8. https://doi.org/10.1007/s1199 9-008-0225-4

19. Rosengren $\mathrm{H}$, Heal CF, Buttner PG. Effect of a single prophylactic preoperative oral antibiotic dose on surgical site infection following complex dermatological procedures on the nose and ear: a prospective, randomised, controlled, double-blinded trial. BMJ Open. 2018;8(4):e020213. https://doi.org/10.1136/bmjopen-2017-020213.

20. Saleh K, Sonesson A, Persson K, et al. Can dressings soaked with polyhexanide reduce bacterial loads in full-thickness skin grafting? A randomized controlled trial. J Am Acad Dermatol. 2016;75(6):1221-8. https://doi. org/10.1016/j.jaad.2016.07.020.

21. Shuman AG, Shuman EK, Hauff SJ, et al. Preoperative topical antimicrobial decolonization in head and neck surgery. Laryngoscope. 2012;122(11):2454-60. https://doi.org/10.1002/lary.23487.

22. Talesh KT, Gargary RM, Arta SA, et al. Effect of $2 \%$ nasal mupirocin ointment on decreasing complications of nasotracheal intubation: a randomized controlled trial. J Clin Diagn Res. 2017;11(8):Pc08-12. https:// doi.org/10.7860/jcdr/2017/29575.10396
23. Tai YJ, Borchard KLA, Gunson TH, et al. Nasal carriage of Staphylococcus aureus in patients undergoing Mohs micrographic surgery is an important risk factor for postoperative surgical site infection: a prospective randomised study. Australas J Dermatol. 2013;54(2):109-14. https://doi. org/10.1111/ajd.12028.

24. Berg HF, Tjhie JH, Scheffer GJ, et al. Emergence and persistence of macrolide resistance in oropharyngeal flora and elimination of nasal carriage of Staphylococcus aureus after therapy with slow-release clarithromycin: a randomized, double-blind, placebo-controlled study. Antimicrob Agents Chemother. 2004;48(11):4183-8. https://doi.org/10.1128/ aac.48.11.4183-4188.2004

25. Konvalinka A, Errett L, Fong IW. Impact of treating Staphylococcus aureus nasal carriers on wound infections in cardiac surgery. J Hosp Infect. 2006;64(2):162-8. https://doi.org/10.1016/j.jhin.2006.06.010.

26. Zibari GB, Gadallah MF, Landreneau M, et al. Preoperative vancomycin prophylaxis decreases incidence of postoperative hemodialysis vascular access infections. Am J Kidney Dis. 1997;30(3):343-8. https://doi. org/10.1016/s0272-6386(97)90277-8.

27. Andenaes K, Lingaas E, Amland PF, et al. Preoperative bacterial colonization and its influence on postoperative wound infections in plastic surgery. J Hosp Infect. 1996;34(4):291-9. https://doi.org/10.1016/s0195 -6701(96)90109-7.

28. Bode LGM, van Rijen MML, Wertheim HFL, et al. Long-term mortality after rapid screening and decolonization of Staphylococcus Aureus carriers observational follow-up study of a randomized placebo-controlled trial. Ann Surg. 2016;263(3):511-5. https://doi.org/10.1097/sla.0000000000 001060.

29. Kalmeijer MD, Coertjens H, Van Nieuwland-Bollen PM, et al. Surgical site infections in orthopedic surgery: the effect of mupirocin nasal ointment in a double-blind, randomized, placebo-controlled study. Clin Infect Dis. 2002;35(4):353-8. https://doi.org/10.1086/341025.

30. Kluytmans J. Reduction of surgical site infections in major surgery by elimination of nasal carriage of Staphylococcus aureus. J Hosp Infect. 1998;40(Suppl B):S25-9. https://doi.org/10.1016/s0195-6701(98)90201-8.

31. Smith $\mathrm{H}$, Borchard $\mathrm{K}$, Cherian $\mathrm{P}$, et al. Randomized controlled trial of preoperative topical decolonization to reduce surgical site infection for Staphylococcus aureus nasal swab-negative mohs micrographic surgery patients. Dermatol Surg. 2019;45(2):229-33. https://doi.org/10.1097/ dss.0000000000001662.

32. Ning J, Wang J, Zhang S, et al. Nasal colonization of Staphylococcus aureus and the risk of surgical site infection after spine surgery: a meta-analysis. Spine J. 2019. https://doi.org/10.1016/j.spinee.2019.10.009.

33. Rohrer F, Notzli H, Risch L, et al. Does preoperative decolonization reduce surgical site infections in elective orthopaedic surgery? A prospective randomized controlled trial. Clin Orthop Relat Res. 2020. https://doi. org/10.1097/corr.0000000000001152.

34. Krezalek MA, Hyoju S, Zaborin A, et al. Can methicillin-resistant staphylococcus aureus silently travel from the gut to the wound and cause postoperative infection? Modeling the "Trojan Horse Hypothesis". Ann Surg. 2018;267(4):749-58. https://doi.org/10.1097/sla.0000000000002173.

35. Garvin KL, Miller RE, Gilbert TM, et al. Late reinfection may recur more than 5 years after reimplantation of THA and TKA: analysis of pathogen factors. Clin Orthop Relat Res. 2018:476(2):345-52. https://doi. org/10.1007/s11999.0000000000000050.

\section{Publisher's Note}

Springer Nature remains neutral with regard to jurisdictional claims in published maps and institutional affiliations. 